\title{
PROPRIEDADES TERMOFÍSICAS DE COMPÓSITO DE MATRIZ DE GESSO E FIBRA VEGETAL
}

\author{
P. W. S. Cunha', U. U. Gomes ${ }^{2}$, R. L. Sivam ${ }^{3}$, G. S. Marinho ${ }^{4}$ \\ Universidade Federal do Rio Grande do Norte \\ ${ }^{1}$ Dpto Enga . Civil - CT, ${ }^{2}$ Dpto Física - CCET, ${ }^{3}$ Dpto Enga . Têxtil - CT, ${ }^{4}$ Dpto Enga Mecânica - CT \\ pwsc@ufrnet.br-umbelino@dfte.ufrn.br-rasiah@ufrnet.br-gmarinho@ct.ufrn.br
}

Artigo submetido em dezembro/2012 e aceito em março/2013

\section{RESUMO}

Foi desenvolvido um compósito de matriz de gesso e reforço de fibra vegetal (Cocos nucifera) destinado à fabricação de elementos construtivos (e. g., placas para forração de coberturas e painéis de vedação). Os corpos de prova foram produzidos na forma de sanduíche de gesso / fibra / gesso. Duas espessuras diferentes da fatia de fibra foram consideradas: $8 \mathrm{~mm}$ e $10 \mathrm{~mm}$. Um corpo de prova de gesso sem a fatia de fibra foi fabricado para servir como padrão de comparação. Utilizando-se um equipamento analisador térmico, foram realizados ensaios para determinação das seguintes propriedades termofísicas dos corpos de prova: condutividade térmica (k), capacidade térmica volumétrica $\left(\rho . C_{P}\right.$ ) e difusividade térmica $(\alpha)$. A partir dos resultados foi possível evidenciar vantagens do compósito em relação ao padrão. O menor valor de $\mathrm{k}$ conferiu ao compósito uma maior capacidade de isolação, possibilitando redução da carga térmica no interior das edificações devido à radiação solar. Nesse aspecto, o compósito se mostra adequado ao uso como elemento de vedação em edificações situadas em localidades de baixas latitudes (e. g., região Nordeste do Brasil). Além das vantagens citadas, o compósito pode proporcionar mais leveza e economia de material, possibilitando a produção de elementos construtivos mais esbeltos.

PALAVRAS-CHAVE: Placas, Compósito, Gesso, Coco, Isolamento térmico.

\section{THERMOPHYSICAL PROPERTIES OF A COMPOSITE WITH MATRIX OF GYPSUM AND REINFORCEMENT OF VEGETAL FIBER}

\begin{abstract}
It was developed a composite with matrix of gypsum and reinforcement of vegetal fiber (Cocos nucifera) to the manufacturing of plates and panels for civil construction. Samples were produced in a sandwich shape of gypsum / fiber / gypsum. Two different thickness of the layer of fiber were considerate: $8 \mathrm{~mm}$ and $10 \mathrm{~mm}$. A sample of gypsum without the layer of fiber was fabricated and used as a standard to comparative study. A thermal analyzer equipment was used to the determination of the thermal conductivity $(k)$, thermal diffusivity $(\alpha)$ and volumetric thermal capacity ( $\rho . C P)$. Based on the results of the tests, it was
\end{abstract}

possible to point out some advantages of the composite comparing with the standard (gypsum). The lower value of $k$ promotes better thermal insulation capacity of the composite, allowing a reduction of the thermal charge inside buildings due to the solar thermal radiation. Thus, the composite seems to be adequate to be applied as a cover element in buildings located at low latitudes (e. g., the Northeast region of Brazil). Beyond the advantages mentioned above, the composite is able to approaching more lightness and economy of material, allowing the production of slim constructive elements.

KEY-WORDS: Plates, Composite, Gypsum, Cocos nucifera, Thermal insulation. 
PROPRIEDADES TERMOFÍSICAS DE COMPÓSITOS DE MATRIZ DE GESSO E FIBRA VEGETAL

\section{INTRODUÇÃO}

O conforto térmico está diretamente associado ao bem estar e à produtividade. Assim, em locais onde a carga térmica implica em condição de desconforto, obrigatoriamente, haverá queda no desempenho do trabalhador e aumento do consumo de energia.

O consumo energético residencial responde por cerca de $40 \%$ da energia produzida no Brasil (Lamberts, Dutra e Pereira, 2004). Por sua vez, a climatização de ambientes é responsável por parcela significativa dessa demanda. Contribuem para isso o clima e as soluções arquitetônicas inadequadas adotadas em parte expressiva das edificações. Em projetos de habitações de interesse social, por exemplo, é comum o uso de placas de PVC para forração das coberturas. A opção por esse tipo de material se deve não somente ao custo, mas, principalmente, à economia do tempo de mão de obra que o mesmo proporciona. Como consequência, os ocupantes são submetidos à condições de desconforto que podem ser atestadas com facilidade (Oliveira, 2010).

A Arquitetura Bioclimática, que prioriza entre outras medidas o melhor aproveitamento da ventilação e iluminação naturais, o maior sombreamento das fachadas e a isolação térmica, vem conquistado interesse de um número crescente de projetistas preocupados com os aspectos ambientais de suas obras, principalmente no que diz respeito à eficiência energética.

Mascaró (1985) estimou que, em regiões de baixas latitudes, caso do Nordeste do Brasil, a carga térmica nas habitações devido à radiação solar se divide em cerca de 70 \% através dos fechamentos horizontais (cobertura) e os 30 \% restantes via fechamentos verticais (parede). Daí a importância de se estudar materiais alternativos para vedação de edificações situadas nessa região.

No presente trabalho são apresentados resultados de análises de propriedades termofísicas de um novo compósito, constituído de matriz de gesso e reforço de fibra de coco (Cocos nucifera), comparadas às propriedades do gesso, convencionalmente utilizado na forração de edificações.

\section{MATERIAIS E PROCEDIMENTOS}

Para desenvolvimento da parte experimental do estudo, os trabalhos foram divididos nas seguintes etapas: fabricação das mantas de fibra de coco, produção do compósito e realização de testes de propriedades termofísicas em laboratório, conforme especificado adiante.

\section{- FABRICAÇÃO DAS MANTAS DE FIBRA DE COCO}

Após o processo de descascamento manual do coco seco para aproveitamento da castanha e da água, a casca, constituída pelo mesocarpo e epicarpo, foi trazida do campo e desfibrada na empresa AQUACOCO - GASPAR ME, localizada no município de Extremoz / RN, com utilização de equipamento próprio, desenvolvido pela mesma (ver Figura 1). 


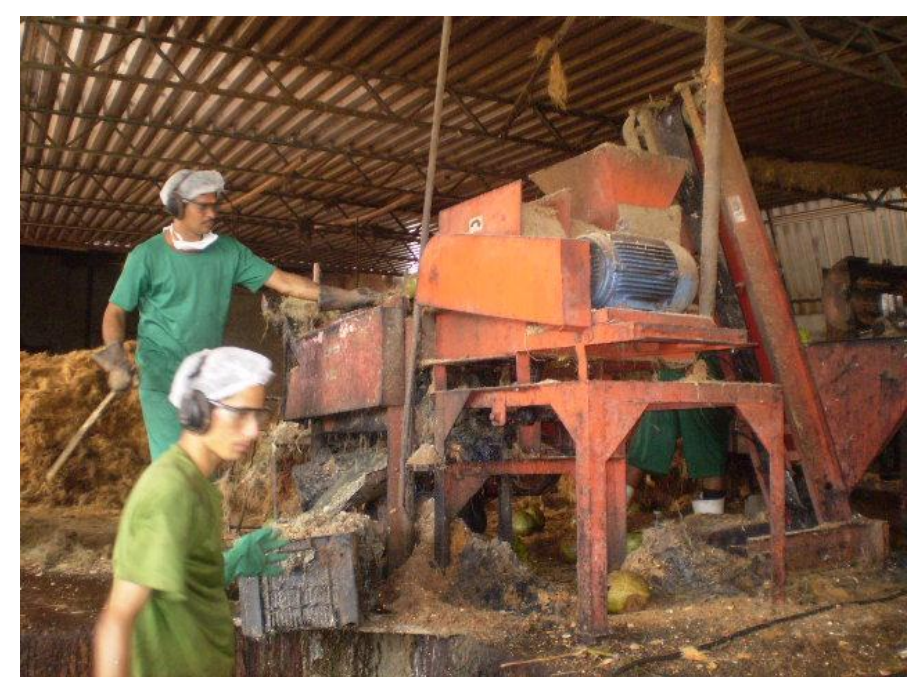

Figura 1 - Máquina de desfibramento da casca do coco (fonte: P. W. S. Cunha, 2012).

A fibra longa de coco seco foi trazida ao Laboratório de Mecânica do IFRN e espalhada sobre uma mesa, sendo então submetida a processo de cardagem manual com o objetivo de promover a remoção das impurezas visíveis, decorrentes do processo de desfibramento (ver Figura 2).

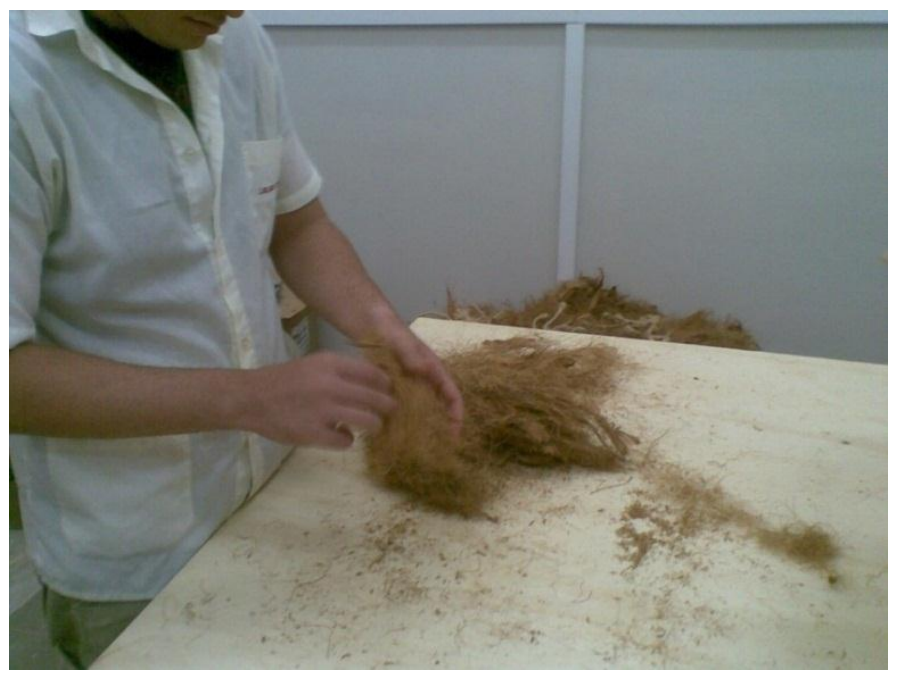

Figura 2 - Cardagem manual da fibra de coco seco (fonte: P. W. S. Cunha, 2012).

Após a operação de cardagem, a fibra foi imersa durante uma hora em solução de água com $4 \%$ de hidróxido de sódio (ver Figura 3), para limpeza e retirada de ceras, gorduras e impurezas superficiais, visando proporcionar melhor aderência à matriz quando da fabricação do compósito. 


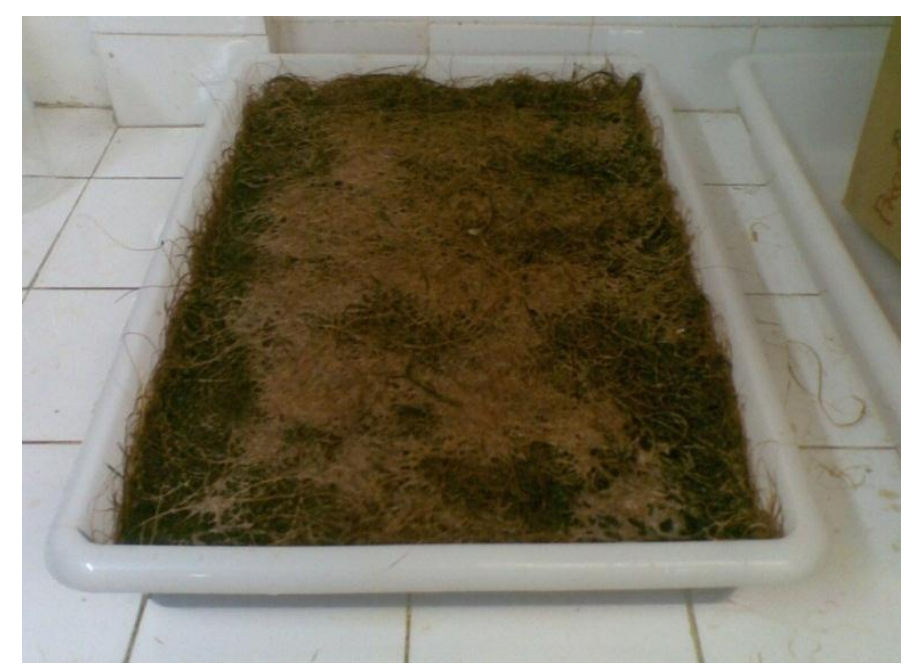

Figura 3 - Fibra sem banho em solução de hidróxido de sódio (fonte: P. W. S. Cunha, 2012).

Após o tratamento, a fibra passou por sucessivas operações de lavagem com água corrente até ser obtido um pH em torno de 7,0 (indicado por meio de papel tornassol). Depois, as fibras foram espalhadas sobre uma bancada localizada em ambiente climatizado para secagem ao tempo, adquirindo o aspecto apresentado na Figura 4. Depois da secagem, realizou-se uma nova operação de cardagem para retirada de resíduos remanescentes, que se tornaram mais visíveis após o tratamento, notadamente aqueles presentes no epicarpo, i.e., parte mais externa da casca de coco.

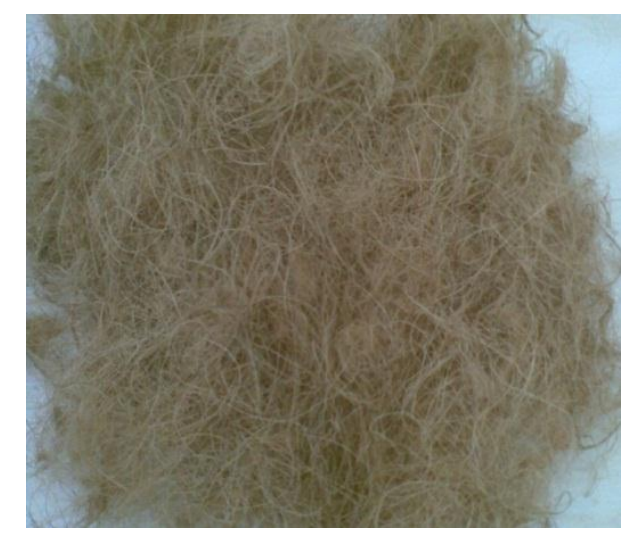

Figura 4 - Fibras após secagem (fonte: P. W. S. Cunha, 2012).

As mantas de fibra de coco foram produzidas utilizando-se um equipamento denominado "confeccionador de manta", idealizado e construído no Laboratório de Mecânica do IFRN, constando de quatro elementos básicos: tanque de vidro, suporte para transporte, prancha para moldagem (superior e inferior) e torneira para escoamento, como pode ser observado na Figura 5. Para confecção das mantas com $8 \mathrm{~mm}$ e $10 \mathrm{~mm}$ foram utilizados $228 \mathrm{~g}$ e $285 \mathrm{~g}$ de fibra de coco, respectivamente. 


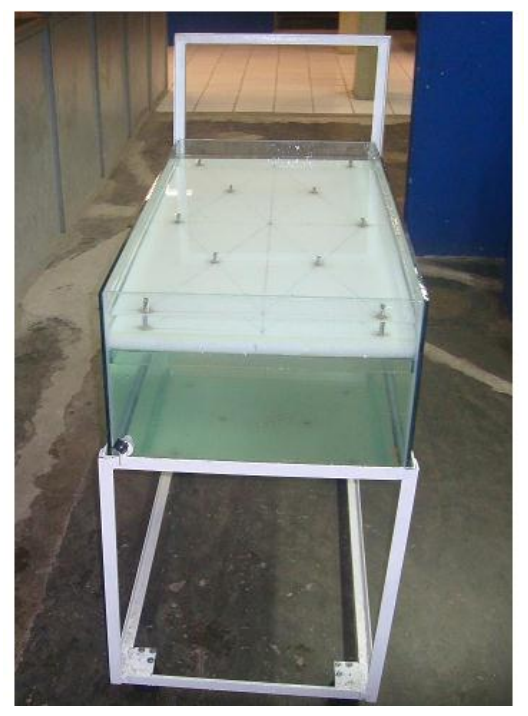

Figura 5 - Confeccionador de mantas, do IFRN (fonte: P. W. S. Cunha, 2012).

Iniciou-se o processo de confecção da manta enchendo-se o tanque com água e distribuindo as fibras manualmente da maneira mais uniforme possível (ver Figura 6).

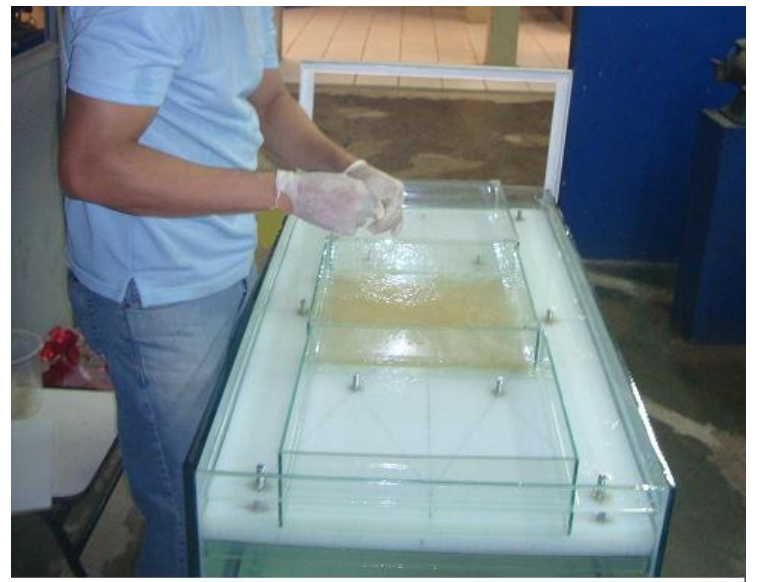

Figura 6 - Fabricação das mantas de fibra de coco no IFRN (fonte: P. W. S. Cunha, 2012).

Finalizada a distribuição das fibras, promoveu-se a drenagem do tanque, obtendo-se a decantação total das fibras sobre a prancha de moldagem inferior do dispositivo. Após a drenagem, parafusos guias foram utilizados para fixar a prancha superior à inferior. Depois disso, as pranchas foram retiradas do dispositivo e a manta contida entre as mesmas foi exposta ao ar livre por três dias para secagem natural, resultando na forma final vista na Figura 7. 


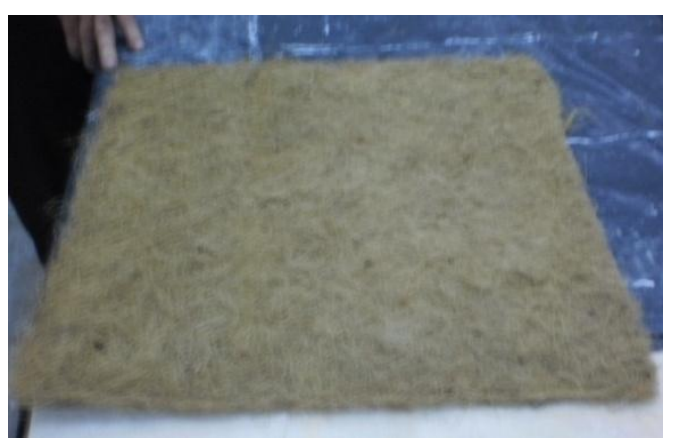

Figura 7 - Manta de fibra de coco produzida no IFRN (fonte: P. W. S. Cunha, 2012).

As mantas foram confeccionadas com dimensões de 1,00 m de comprimento por $0,50 \mathrm{~m}$ de largura, correspondendo a pesos de 223,40 g e 279,30 g para espessuras médias de $8 \mathrm{~mm}$ e 10 $\mathrm{mm}$, respectivamente. As medidas de espessura foram efetuadas em quatro pontos de cada manta, escolhidos aleatoriamente.

\section{- FABRICAÇÃO DOS COMPÓSITOS DE GESSO E FIBRA DE COCO}

De posse das mantas de fibra de coco, procedeu-se a fabricação dos compósitos de matriz de gesso e reforço de fibra. A manta com fibras alinhadas ocupava a parte central, compondo um sanduíche de gesso + fibra + gesso, conforme representado na Figura 8.

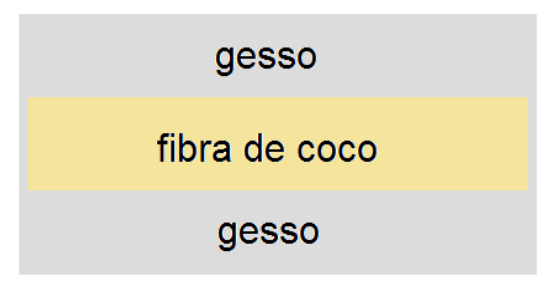

Figura 8 - Compósito de matriz de gesso e reforço de fibra de coco (fonte: P. W. S. Cunha, 2012).

Foram produzidos corpos de prova de gesso (padrão, C-0) e de compósito gesso/fibra. Os compósitos, confeccionados no Laboratório de Mecânica do IFRN sobre uma bancada de madeira forrada com lona plástica (ver Figura 9), foram constituídos de sanduíche de gesso com fibra de coco, com dimensões de: $8 \mathrm{~mm}$ de gesso $+8 \mathrm{~mm}$ de fibra $+8 \mathrm{~mm}$ de gesso (amostra C-8); e $7 \mathrm{~mm}$ de gesso $+10 \mathrm{~mm}$ de fibra $+7 \mathrm{~mm}$ de gesso (amostra C-10). Cada amostra tinha dimensões de $500 \mathrm{~mm} \times 500 \mathrm{~mm} \times 24 \mathrm{~mm}$. Utilizou-se o gesso INGEL para fundição. Na Figura 10 observam-se as etapas de fabricação. 


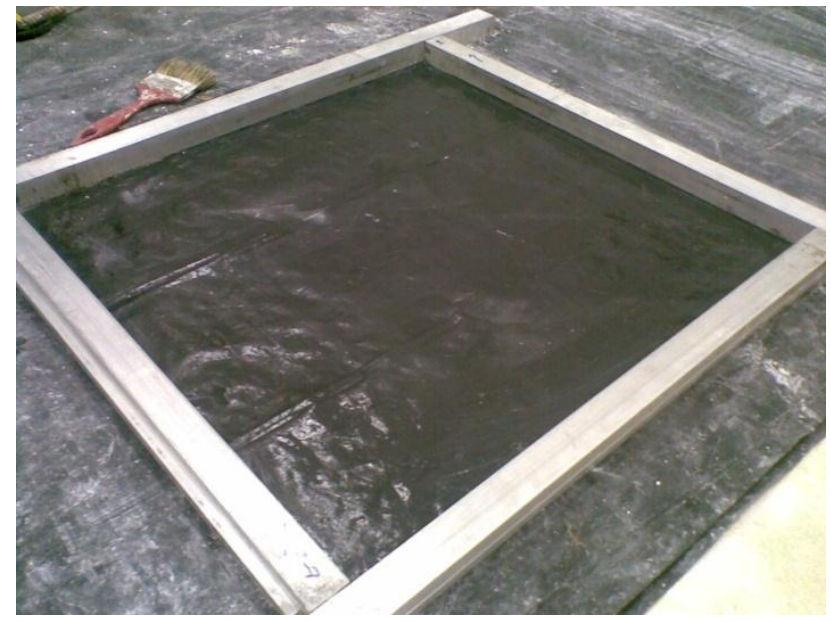

Figura 9 - Moldes de fabricação dos compósitos (fonte: P. W. S. Cunha, 2012).
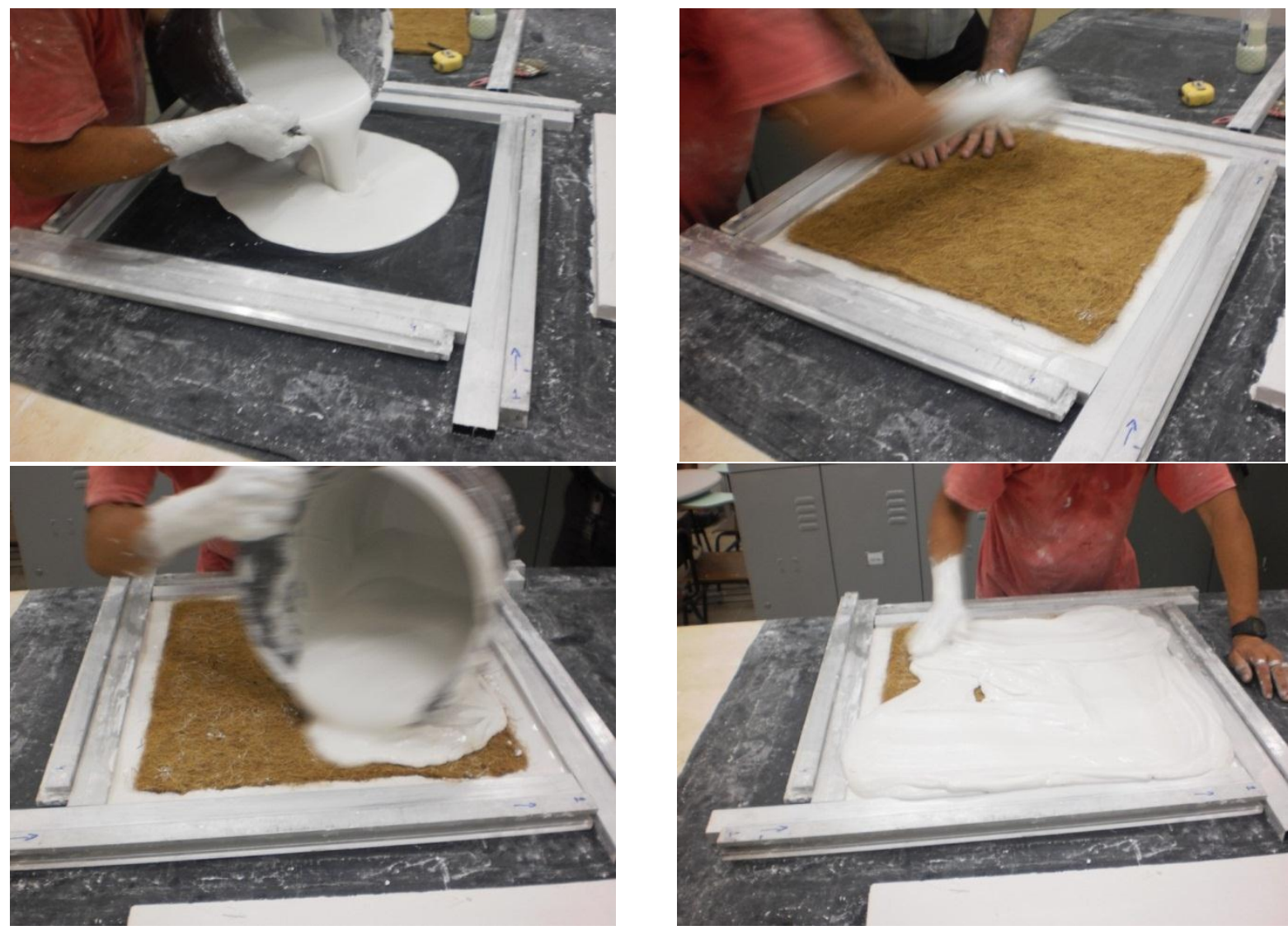

Figura 10 - Etapas do processo de fabricação dos compósitos (fonte: P. W. S. Cunha, 2012).

\section{- DETERMINAÇÃO DE PROPRIEDADES TERMOFÍSICAS}

As propriedades termofísicas das amostras foram determinadas por meio do equipamento THERMAL PROPERTIES ANALYZER, modelo Quickline TM - 30, pertencente ao Laboratório de Geologia da UFRN, fabricado pela empresa Anter Corporation/USA. As medidas de condutividade térmica $(\mathrm{W} / \mathrm{m} . \mathrm{K})$, difusividade térmica $\left(\mathrm{m}^{2} / \mathrm{s}\right)$ e capacidade térmica volumétrica 
$\left(\mathrm{J} / \mathrm{m}^{3} \mathrm{~K}\right)$ são baseadas em registros periódicos da temperatura em função do tempo de resposta à excitação térmica da amostra por meio de fluxo de calor direcional. O fluxo é gerado por aquecimento elétrico de um resistor inserido no sensor, que é colocado em contato direto com o material a ser analisado. Na Figura 11 observa-se o equipamento utilizado neste trabalho.

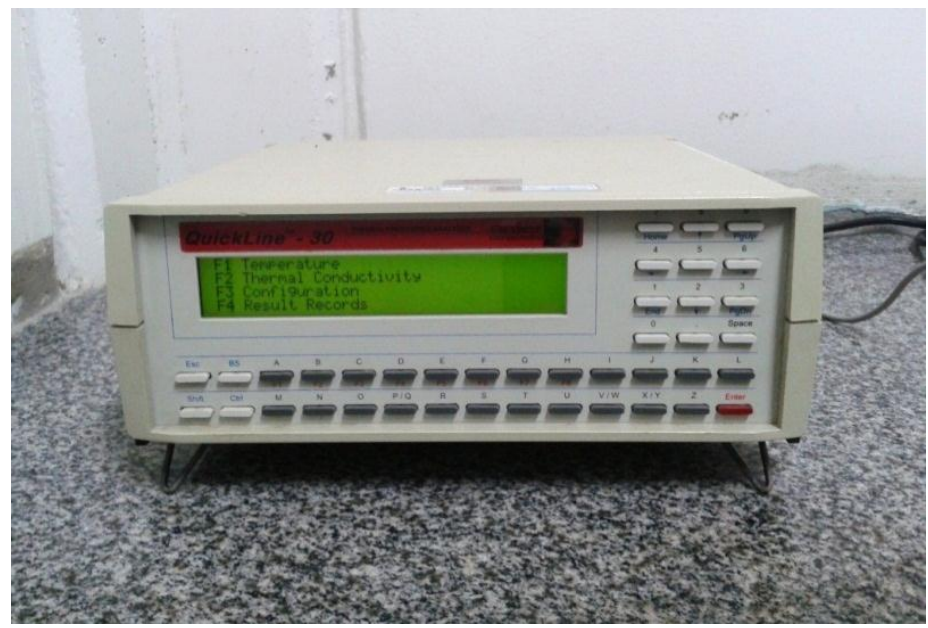

Figura 11 - Analisador de propriedades termofísicas do Laboratório de Geologia da UFRN (fonte: P. W. S. Cunha, 2012).

As amostras foram analisadas utilizando-se o sensor (8120010), próprio para faixa de 0,3 a $2 \mathrm{~W} / \mathrm{m}$.K. A escolha do sensor foi feita levando-se em consideração os valores médios da condutividade que se estima obter, com base no tipo de material e em informações obtidas na literatura técnica (Ozisik, 1990). Para eliminar o ar entre a amostra e o sensor, o fabricante recomenda utilizar pasta térmica. Entretanto, esse procedimento foi desnecessário em função do tipo de material analisado, cuja superfície, muito plana e homogênea, permitia um perfeito acoplamento entre as duas partes (ver Figura 12). Para cada amostra, foram realizadas medições em cinco pontos diferentes, conforme gabarito apresentado na Figura 12.
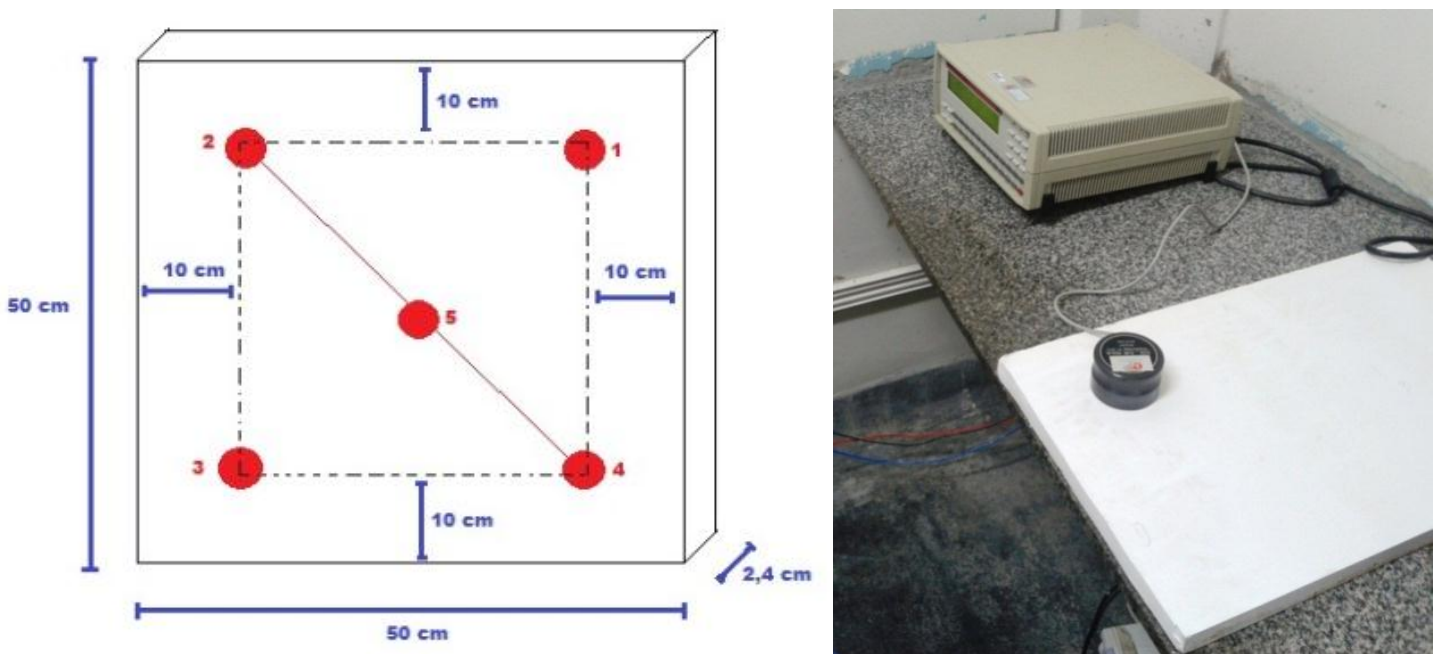

Figura 12 - Gabarito de medição e sensor instalado sobre amostra durante análise (fonte: P. W. S. Cunha, 2012). 


\section{RESULTADOS E DISCUSSÃO}

Na Figura 13 observam-se os resultados da variação da condutividade térmica (k) em função da espessura da manta de fibra de coco, onde a espessura "zero" corresponde à placa padrão de gesso sem fibra.

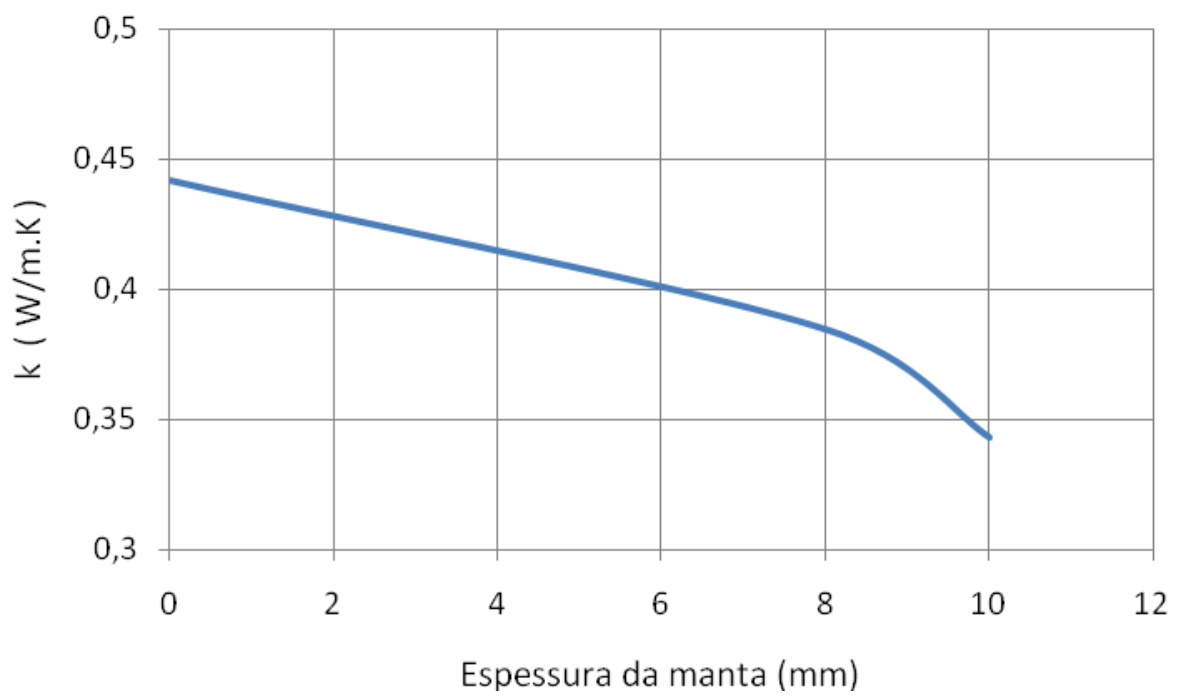

Figura 13 - Condutividade térmica em função da espessura da manta (fonte: P. W. S. Cunha, 2012).

Comparados ao corpo de prova padrão de gessos em fibra (C-0), os compósitos com $8 \mathrm{~mm}$ (C-8) e com $10 \mathrm{~mm}$ (C-10) de fibra apresentaram uma redução de cerca de $13 \%$ e $22 \%$ no valor de $k$, respectivamente. Considerando-se que a condutividade térmica do gesso vale aproximadamente $0,48 \mathrm{~W} / \mathrm{m} . \mathrm{K}$ (Ozisik, 1990), acredita-se que o fato observado foi motivado mais pelo ar aprisionado entre as fibras que ao ar presente no interior (lúmem) das fibras.

Na Figura 14 apresentam-se os resultados da capacidade calorífica volumétrica ( $\left.\rho . C_{\mathrm{P}}\right)$.

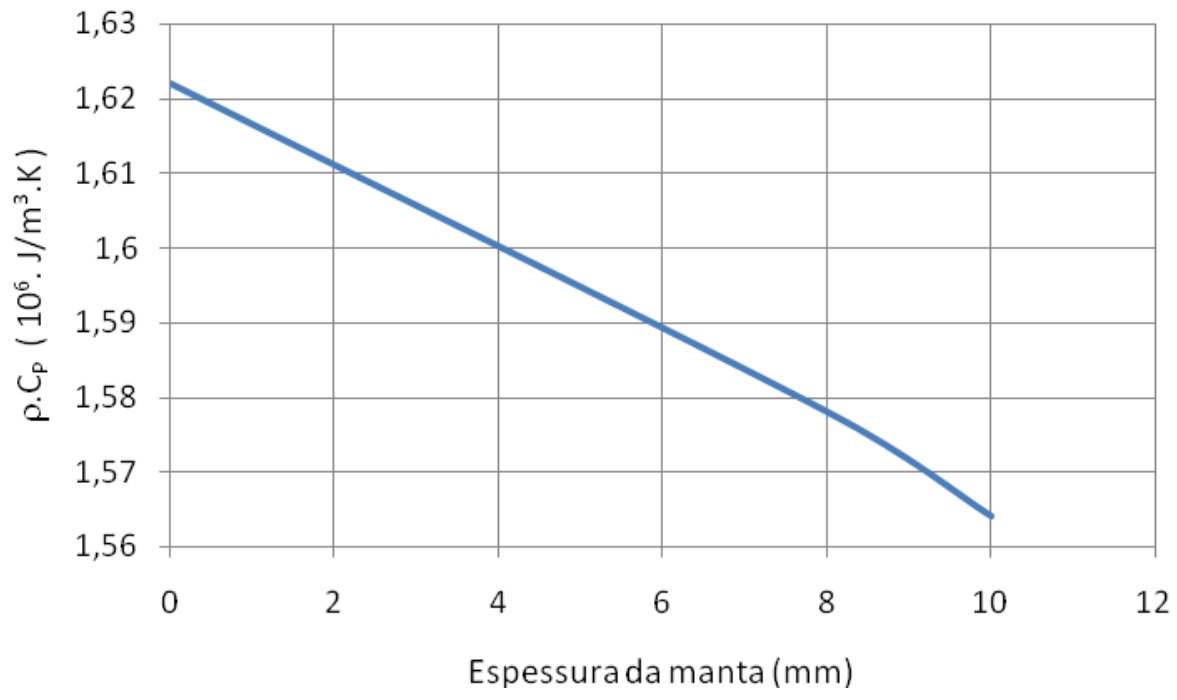

Figura 14 - Capacidade calorífica volumétrica em função da espessura da manta (fonte: P. W. S. Cunha, 2012). 
Ocorreram reduções de cerca de $5 \%$ e 6 \%, respectivamente para os compósitos C-8 e C10 , em comparação ao valor determinado para a amostra padrão C- 0 . Deve-se destacar aqui que os valores obtidos para $\rho . C_{p}$ são multiplicados por $10^{6} \mathrm{~J} / \mathrm{m}^{3} . \mathrm{K}$, razão pela qual as diferenças observadas apenas parecem ser insignificantes.

Sendo essa propriedade termofísica um indicador da quantidade de energia necessária à alteração da temperatura dos corpos quando esses são submetidos a uma fonte térmica de magnitude constante, a diferença é, antes de tudo, muito representativa do ponto de vista de consumo/economia de energia necessária à obtenção de conforto térmico no interior de habitações, especialmente se o processo para se atingir essa condição for obtido por meio de aparelho condicionador de ar.

Na Figura 15 mostram-se os resultados da difusividade térmica $(\alpha)$.

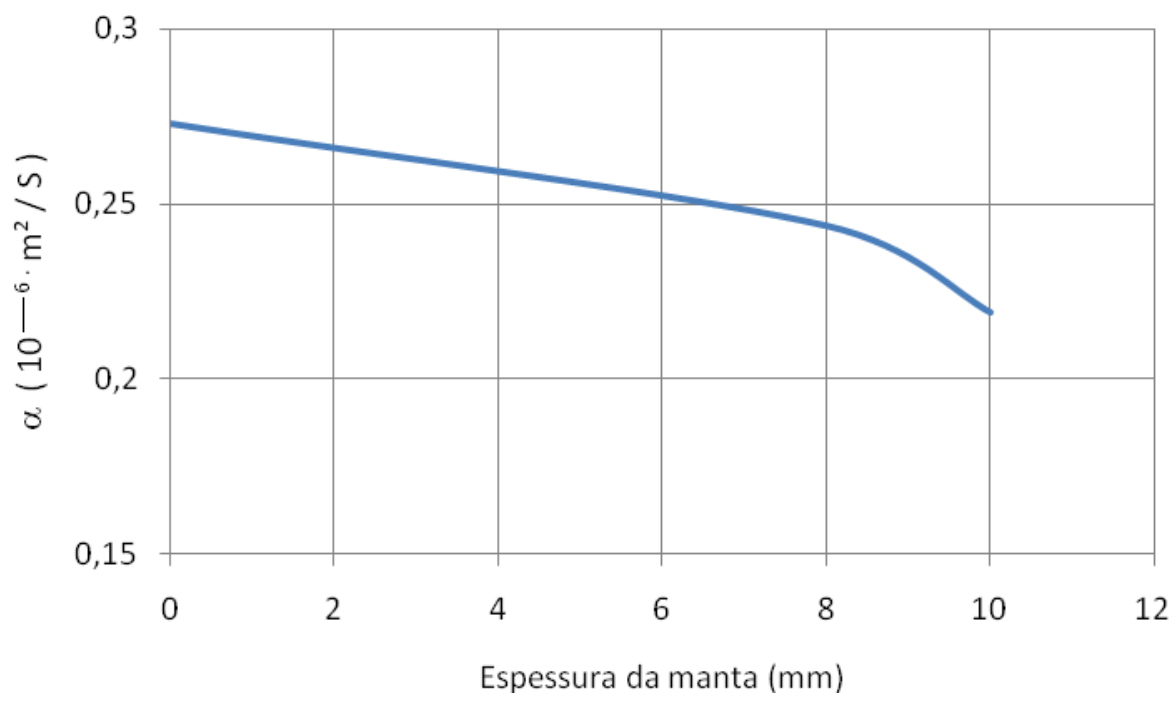

Figura 15 - Difusividade térmica em função da espessura da manta (fonte: P. W. S. Cunha, 2012).

Os valores da difusividade térmica dos compósitos C-8 e C-10 diminuíram aproximadamente 10 \% e 20 \%, respectivamente, em relação ao valor da amostra padrão C-0. Matematicamente, $\alpha$ é dada por:

$$
\alpha=k / \rho \cdot C_{p}
$$

equação (1)

Constatou-se uma diferença desprezível entre os valores medidos e aqueles determinados por meio da equação 1. Essa propriedade está relacionada à velocidade com que o calor flui através do material durante as variações de temperatura com o tempo (Ozisik, 1990). Quanto maior seu valor, mais rapidamente o calor se propagará no meio. Assim, a redução no valor de $\alpha$ pode ser associada a um tempo maior para que o calor penetre no meio. Portanto, nesse caso, o resulta do é bem-vindo. 


\section{CONCLUSÕES}

Visando reduzir o problema do desconforto térmico em habitações de interesse social, o governo federal buscou apoio na academia. O resultado dessa parceria foi a elaboração de normas de desempenho térmico de edificações, NBR - 15220 (ABNT, 2005). Anteriormente, outra iniciativa governamental com apoio da academia foi desenvolvida a partir de 1985, com a instituição do PROCEL - Programa de Combate ao Desperdício de Energia Elétrica. Portanto, governo e academia estão tentando resolver o problema, e já dispõem de alguns resultados, faltando apenas alguém avisar à iniciativa privada que existem alternativas para solucionar os problemas de conforto térmico nas habitações e que essas alternativas gozam do privilégio de terem sido desenvolvidas aqui.

É intrigante constatar que, apesar do profissional da Construção Civil ter conhecimento qualitativo da parcela de energia que chega ao interior via cobertura em habitações localizadas na região Nordeste do Brasil, pouca atenção é dispensada ao problema da isolação térmica dos elementos de forração do teto.

Um dos principais desafios da construção civil é o desenvolvimento de materiais que proporcionem uma relação adequada entre leveza e resistência mecânica. A Arquitetura Bioclimática, por sua vez, está interessada em associar o fator resistência térmica $\left(R_{T}\right)$ a essas duas variáveis. Assim, garantida a relação leveza / resistência mecânica, procura-se modificar um determinado material para obter um aumento de $\mathrm{R}_{\mathrm{T}}$. Sendo essa variável inversamente proporcional ao coeficiente de condutividade térmica (k), as reduções (entre $13 \%$ e $22 \%$ ) nos valores de $\mathrm{k}$ observadas nos experimentos com $\mathrm{o}$ material desenvolvido nesta pesquisa representam uma contribuição à área.

Além da redução da capacidade calorífica volumétrica ( $\left.\rho . C_{p}\right)$ - propriedade associada à retenção de energia no interior da matéria, a difusividade térmica $(\alpha)$ do compósito desenvolvido apresentou reduções que variaram entre $10 \%$ e $20 \%$ quando comparado ao elemento construtivo padrão (gesso sem fibra). Como $\alpha$ representa a velocidade com que a energia térmica flui através da matéria, reduzir seu valor implica em retardar a passagem de calor do meio externo ao interior da habitação. Consequentemente, seu emprego no envelope exterior de uma habitação poderá resultar em menor carga térmica a ser removida por meio de condicionadores de ar e, portanto, poderá promover economia de energia elétrica.

Apesar das vantagens observadas nos valores das propriedades termofísicas do compósito em comparação ao padrão, o material ainda carece de análises de desempenho térmico. Essa próxima etapa da pesquisa servirá para reforçar a viabilidade do novo material. A inserção de fibra vegetal em elemento construtivo, além de promover a redução do peso da edificação, agrega valor a uma matéria prima abundante na região. De baixo custo, eficiente e utilizando riquezas (fibras) locais para solução de um problema intrínseco à própria região, a tecnologia desenvolvida tem nas simplicidades de concepção, produção e aplicação seus maiores méritos. 


\section{AGRADECIMENTOS}

O desenvolvimento desta pesquisa só se tornou possível graças aos apoios obtidos dos junto à empresa AQUACOCO - D. D. GASPAR ME, ao Laboratório de Mecânica do Instituto Federal de Educação, Ciência e Tecnologia do Rio Grande do Norte (IFRN) e ao Laboratório de Geologia da Universidade Federal do Rio Grande do Norte (UFRN).

\section{REFERÊNCIASBIBLIOGRÁFICAS}

1. ABNT. Desempenho térmico de edificações. Parte 3: Zoneamento bioclimático brasileiro e diretrizes construtivas para habitações unifamiliares de interesse social. NBR15220-3. Rio de Janeiro, ABNT, 2005, 7 p.

2. LAMBERTS, R., DUTRA, L., PEREIRA, F. O. R. Eficiência Energética na Arquitetura. São Paulo: P W Editores, 2004, 2.ed., $188 \mathrm{p}$.

3. MASCARÓ, L. R. Energia na Edificação - Estratégias para minimizar seu consumo. São Paulo, Projeto Editores Associados, 1985.

4. OLIVEIRA, R. P. Utilização de um aplicativo de simulação computacional na avaliação de desempenho térmico de protótipos de Habitação de Interesse Social. Dissertação (Mestrado em Arquitetura e Urbanismo) - Universidade Federal do Rio Grande do Norte. 2010, 124 p.

5. OZISIK, M. N. Transferência de calor, um texto básico. Rio de Janeiro, Guanabara Dois, 1990, pp.634. 